\title{
Better times to come? \\ Intergenerational class mobility of labour market entrants in Germany and the UK since the 1950s ${ }^{\dagger}$
}

\author{
Nhat An Trinh ${ }^{*}$ and Erzsébet Bukodi*
}

April 2020

[For a published version in the European Sociological Review (accepted June 2021)

see https://doi.org/10.1093/esr/jcab028.]

\begin{abstract}
This study examines over-time trends in intergenerational class mobility based on cohorts of labour market entrants in Germany and the UK since the 1950s. We calculate absolute and relative mobility rates, separately for men and women, using the German Socio-Economic Panel (1984-2016), the UK Household Longitudinal Study (2009-2016), and the UK Labour Force Survey (2014-2017). Regarding absolute mobility, we find marked country differences in upward and downward rates. In Germany, downward mobility decreased, while upward mobility rose. In the UK, downward mobility increased, while upward mobility declined. We provide evidence that these differences can be linked to contrasting changes in the distribution of origin and destination classes. Regarding relative mobility, striking country similarities appear. For both countries, we observe increases in social fluidity for respondents entering the labour market during the 1950s and 1960s that cease to continue for cohorts thereafter. Comparisons between adjacent cohorts do not provide evidence that social fluidity follows cyclical developments of the economy or shorter-term volatilities in the labour market.
\end{abstract}

Keywords: Social mobility, social class, labour market entry, over-time change, Germany, UK

\footnotetext{
† We would like to thank John Goldthorpe, Caspar Kaiser and Colin Mills for their extensive and insightful comments on earlier drafts. We also thank members of the Social Inequality Research Group and participants of the DSPI Graduate Research Student Conference at the University of Oxford for their stimulating questions and useful suggestions. Special thanks go to the UK Data Service for providing invaluable support and access to the Secure Access Version of the UK Labour Force Survey.

* Corresponding author: nhatan.trinh@,wolfson.ox.ac.uk, Department of Social Policy and Intervention, Wolfson College, University of Oxford.

** erzsebet.bukodi@nuffield.ox.ac.uk, Department of Social Policy and Intervention, Nuffield College, University of Oxford.
} 


\section{Introduction}

For almost a century, scholars examine to what extent the association between individuals' class origins and class destinations changes over time to further our understanding of the pattern and determinants of the intergenerational transmission of inequality. Conceptually derived from employment relations, social class predicts individuals' level of wealth as well as income stability, security and prospects due to stratified renumeration schemes and risks of unemployment (Bukodi and Goldthorpe 2018). Accordingly, a class gradient in individuals' livelihoods and opportunities has been shown to exist in many countries (e.g. Lareau and Conley 2008; Groh-Samberg 2009; Bukodi and Goldthorpe 2018).

There is now general agreement that absolute class mobility, i.e. the proportion of individuals who attain a different class position compared to their parents, displays significant variation over time, and that this variation is primarily driven by changes in the form of class structures (e.g. Erikson and Goldthorpe 1992; Breen and Luijkx 2004; Bukodi et al. 2019). However, regarding trends in relative class mobility or social fluidity, i.e. the strength of the association between individuals' and their parents' class positions net of distributional differences, the literature has yielded much less consistent results.

Studies that find gradual increases in social fluidity during the twentieth century suggest that relative mobility rates largely follow structural developments induced by modernisation (Treiman 1970; Bell 1972; Ganzeboom et al. 1989). In contrast, studies that find increases in social fluidity only for individuals born before the 1950s link these to educational expansion and reductions in educational inequalities that slowed down for individuals born thereafter (Breen and Müller 2020). Others, again, focus on the notion of cohort replacement as trends are thought to be shaped by the entry and exit of cohorts with varying levels of social fluidity (Ryder 1965; Breen and Jonsson 2007; Mayer and Aisenbrey 2007); while those who find relative mobility to remain stable, being at most subject to 'trendless fluctuation', stress the ability of families at the top of the class hierarchy to pass on their advantage to the next generation regardless of societal change (Featherman and Hauser 1978; Erikson and Goldthorpe 1992; Bukodi and Goldthorpe 2018).

Most studies cited above rely on 'quasi'-birth cohorts, or simple age groups, to map trends and patterns of absolute and relative mobility. This approach can be problematic for two reasons. First, using quasi-birth cohorts inevitably confounds inter- and intragenerational mobility. Prospective cohort studies are rarely available. Researchers thus need to construct birth cohorts from surveys that are representative of an entire population at a given point in time. Consequently, members of older cohorts are observed at later stages in their careers, while members of younger cohorts are observed at earlier stages. This introduces bias to the estimation of over-time change. Setting a minimum age for individuals to be included in the analysis controls for this only to a limited extent, since 'occupational maturity', i.e. the point at which job changes no longer entail changes in class positions, likely varies across time and across cohorts (see Bukodi and Goldthorpe 2009 for Britain).

Second, due to differences in educational attainment and educational trajectories, members of the same birth cohort begin their employment careers at different points in time. If some start working after completing compulsory schooling while others pursue a tertiary degree, labour market entries can lie up to ten years apart. Thus, members of the same cohort are likely to start their careers 
under quite different economic, labour market and institutional conditions that could affect their later mobility prospects. Quasi-birth cohorts hence do not allow to precisely determine the timing of change in intergenerational mobility and to account for the opportunity structures its members are faced with.

Against this background, the objective of the present study is to use cohorts of labour market entrants to investigate trends in both absolute and relative class mobility. This approach addresses both critiques of the quasi-birth cohort approach: Individuals who enter the labour market at the same time are always found at comparable career stages due to similar levels of work experience and are by definition exposed to the same conditions at the start of their working lives. The approach has therefore not only the potential to explore long-run trends in intergenerational class mobility in a more accurate way, helping to evaluate the inconclusive findings of prior work on trends in relative mobility described above. It is also useful for shedding light on the relationship between class mobility and the business cycle as well as other short-term changes occurring to the labour market. Past research in fact shows that entering the labour market under adverse economic conditions has strong and enduring 'scarring' effects on future trajectories and class attainment in a number of European countries, and differently so for individuals from different social backgrounds (Blossfeld 1986, 1987; Bukodi and Goldthorpe 2011; Barone and Schizzerotto 2011).

We hence see our contribution as twofold. Focussing on the association between class origin and class destination at labour market entry, we first map long-term trends that purely result from cohort differences in intergenerational mobility, and are thus 'adjusted' for intragenerational mobility, from the second half of the last century until today. Second, we examine shorter-term changes between labour market entry cohorts over the same period to understand how far mobility chances can be systematically linked to conditions of the economy or the labour market, under which individuals embark on their careers.

Evidently, it is possible that the long-run trends that we observe for labour market entrants differ from those observed for individuals at later career stages. The main reason is that over the course of their working lives individuals tend to move between different class positions, which may also entail quite substantial mobility intergenerationally. Further, past research shows that patterns of labour market entry and career progression unfold very differently, depending on the institutional context in which they occur (Blossfeld et al. 2005; Scherer 2005; Wolbers 2007; Barbieri et al. 2016). Differences between trends in intergenerational class mobility based on class destination measured at labour market entry vis-à-vis later career stages could then depend on a country's level of career mobility.

We therefore adopt a comparative perspective and conduct our analyses for two countries, for which past research has demonstrated maximally different levels of career mobility - Germany and the UK (Blossfeld et al. 2008). This comparative design allows us to explore how far differences in trends of intergenerational class mobility between labour market entrants and individuals at more advanced career stages may result from differing levels of career mobility. Germany and the UK figure prominently in the mobility literature. For both countries, there exists a large and established body of evidence on trends in intergenerational class mobility for individuals at more advanced career stages, albeit based on quasi-birth cohorts. Our results can therefore be meaningfully contrasted with prior work. 
The next section reviews in greater depth past research on Germany and the UK and discusses to what extent our results using labour market entry cohorts can add to previous studies using quasibirth cohorts. We then elaborate on our data and key variables and present the empirical results in the following sections. The article ends with a summary of our findings and discussion of their implications for future research.

\section{Past research and theoretical expectations}

\section{Absolute mobility}

As said, absolute mobility refers to the proportion of individuals who attain different class positions (class destination) than their parents' position (class origin), which might be at higher, lower or broadly similar levels. Absolute mobility can therefore be divided into upward, downward and horizontal components. Past research finds quite similar trends for Germany and the UK. In both countries, overall mobility levels remained generally stable throughout the twentieth century, that is around 70-80 per cent of individuals ended up in different class positions from that of their parents (Breen 2004). Likewise, similar developments can be observed with regard to the long-run trends in the upward and downward components of absolute mobility. For Germany, Mayer and Aisenbrey (2007), Müller and Pollak (2015) (see also Pollak and Müller 2020) as well as Hertel (2017) report increasing upward mobility for cohorts born in the first half of the twentieth century, and a decline in these rates for cohorts born thereafter. By contrast, downward mobility fell among earlier cohorts before starting to rise among later cohorts. For the UK, a similar reversal of trends in upward and downward mobility can be observed when comparing studies covering cohorts born before (Goldthorpe, Llewellyn, and Payne 1987) and after 1950 (Goldthorpe and Jackson 2007; Paterson and Iannelli 2008; Bukodi et al. 2015; Buscha and Sturgis 2018).

These similar developments in absolute mobility were driven by common class structural changes that occurred simultaneously in Germany and the UK as well as in other industrialised countries (Erikson and Goldthorpe 1992; Breen 2004; Breen and Müller 2020). Cohorts born in the first half of the twentieth century experienced a period of occupational upgrading, primarily due to the stark rise of skilled service jobs alongside the decline of the agricultural sector and unskilled manual work. Greater room at the top improved chances for upward mobility and made downward mobility less likely. However, for cohorts born thereafter occupational upgrading came to a halt and as the proportion of individuals with higher class origins had been rising, so did the proportion of men and women 'at risk of downward mobility' (Bukodi et al. 2019).

Changes in the distribution of origin and destination classes may yet look different depending on the point at which individuals are observed in their careers, and differently so in Germany and the UK. Germany's combination of an occupation-specific education and training system with a tightly regulated labour market facilitates stable labour market entries and high degrees of job continuity (Scherer 2005; Leuze 2007). Levels of career mobility are therefore low, and individuals tend to stay in similar class positions throughout their working lives. As a result, class distributions are likely to be quite similar for individuals at different stages of their careers. We therefore expect trends in absolute mobility for labour market entrants in Germany to resemble those observed in past research. 
In contrast, in the UK, the coordination between educational and labour market institutions is weak. Combined with high labour market flexibility, labour market entries are unstable and levels of career mobility high (Scherer 2005; Leuze 2007). Individuals from more advantaged backgrounds are thus more likely than their German counterparts to experience some turbulence in their early careers, possibly leading to intergenerational downward mobility before settling in more stable employment and reaching similar positions as their parents through upward career mobility - a phenomenon known as 'counter mobility' (Bukodi and Goldthorpe 2018). Consequently, class distributions may look rather different depending on whether individuals are observed earlier or later in their careers. We therefore expect trends in absolute mobility for labour market entrants in the UK to differ from those observed in past research, and thereby to also be different from trends observed for labour market entrants in Germany.

\section{Relative mobility}

Relative mobility or social fluidity refers to the strength of the association between individuals' origins and destinations net of differences in the class distributions between the parents' and children's generation. For our two countries, previous studies find rather different trends in relative mobility. In Germany, increasing rates were observed for cohorts born in the first half of the twentieth century, which then levelled off and remained stable for cohorts born during the second half of the twentieth century (Hertel 2017; Pollak and Müller 2020). By contrast, in the UK, a picture of no change was found for individuals born over the same period of time (Goldthorpe and Jackson 2007; Paterson and Iannelli 2008; Bukodi et al. 2015).

To account for these patterns, the literature refers to processes affecting the associations summarised in the so-called 'OED triangle' between individuals' class origin $(\mathrm{O})$, educational attainment (E), and class destination (D) that are suggested to have unfolded differently in the two countries. Besides some decrease in the ED association, cohorts born in Germany before the 1950s experienced a decline in the strength of the OE and the OD associations as the expansion of education reduced class-based educational inequalities and increased the proportion of the highereducated, for whom a weaker origin-destination association net of education exists. As a result, social fluidity increased. However, as the population became increasingly educated, opportunities for a further weakening of these associations diminished and relative rates ceased to rise for cohorts born thereafter (Müller and Pollak 2004; 2015; Pollak and Müller 2020; Hertel 2017).

In the UK, trends in these associations were much more stable despite educational expansion. If any, a weakening in the OE association could be observed (Jonsson and Mills 1993; Breen at al. 2009) that was yet likely counteracted by a simultaneously weakening in the ED association (Goldthorpe and Mills 2004; Breen and Luijkx 2004; Jackson et al. 2005), primarily due to overqualification and 'credentials inflation' (Bukodi and Goldthorpe 2018). Bukodi and Goldthorpe (2016) also show that when measuring education in relative terms, the associations between OE and ED remained essentially unchanged. With no further changes in the direct OD association (Gugushvili et al. 2017), social fluidity stayed constant for cohorts born across the twentieth century.

Again, it is possible that trends in the associations captured by the OED triangle differ for individuals at different career stages, i.e. they may depend on when we measure $\mathrm{D}$, and that these 
differences in turn depend on levels of career mobility. If career mobility is low, changes in class positions are rare so that the $\mathrm{OE}, \mathrm{ED}$, and $\mathrm{OD}$ associations are unlikely to vary in any great strength over the course of individuals' working lives. We thus expect trends in relative mobility for labour market entrants in Germany to resemble those observed in past research. High career mobility, on the other hand, means that changes in class positions occur more frequently, leading to variation especially in the ED and OD associations across individuals' careers. The prevalence of counter mobility further implies that the ED and OD associations could be particularly weak at labour market entry for individuals from higher class backgrounds. ${ }^{2}$ Focussing on first job may then reveal more variation in relative mobility than previously reported, which would be in line with Bukodi et al. (2015), who find social fluidity to increase when members of birth cohorts are observed at a younger age. We therefore expect trends in relative mobility for labour market entrants in the UK to differ to some extent from those observed in past research.

Using cohorts of labour market entrants not only complements prior work on long-term trends in intergenerational class mobility. As we argued at the beginning, a further strength is that this approach allows to precisely explore whether shorter-term changes in relative mobility can be systematically linked to changes in conditions of the economy and the labour market. There is evidence suggesting that individuals whose labour market entries coincided with a period of severe economic difficulties, continuing high levels of unemployment, and labour market re-structuring experienced significantly slower improvements in their earnings and occupational status compared to those who started their careers under more favourable conditions (Blossfeld 1986, 1987; Bukodi and Goldthorpe 2011; Barone and Schizzerotto 2011). Moreover, such adverse economic conditions seem to disproportionally affect individuals from lower class origins. For the UK, Bukodi and Goldthorpe (2011) show that coming from more advantaged backgrounds helps to offset the relatively low earnings and occupational returns that individuals obtained from high-level qualifications during periods of unfavourable labour market conditions, and that such an advantage was still apparent at later career stages. Given these findings, we expect periods of economic 'bust' to be associated with decreases in social fluidity, and periods of 'boom' to be associated with increases in social fluidity.

\section{Data and variables}

As our objective is to map trends in intergenerational class mobility as detailed as possible from the second half of the last century until today, we use large-scale surveys that cover the period in question. For Germany, our analyses are based on waves 1984-2016 of the German SocioEconomic Panel (SOEP). The SOEP is the largest representative, longitudinal survey in Germany interviewing each year around 30,000 respondents in ca. 11,000 households on matters relevant to social inequality research. To ensure comparability over time, we only work with the West German sample of the survey. ${ }^{3}$

\footnotetext{
2 Bukodi (2017) shows that in the UK further education serves as a channel through which individuals from higher class backgrounds strengthen the OD association and achieve counter mobility.

3 That is, only respondents who entered the labour market in West Germany are included in the analytical sample. However, $7.22 \%$ of respondents who entered the labour market in West Germany after 1989 were born in East
} 
For the UK, we use two datasets. Our primary dataset is the UK Household Longitudinal Study (UKHLS, End User License version), also known as Understanding Society. Like the SOEP, the UKHLS is the largest representative, longitudinal multi-topic study that is annually conducted in the UK. Covering roughly 145,000 respondents in ca. 40,000 household, it started in 2009. We therefore use waves 2009-2016. Our secondary dataset consists of the 2014-2017 UK Labour Force Survey (UKLFS, Secure Access version). The UKLFS collects representative information on current employment conditions on a quarterly basis and is currently the UK's largest household survey. Since 2014, the UKLFS also collects, in each July-September Quarter, data on the characteristics of parents' employment during respondents' childhood, which makes it suitable for our purposes. It is based on a rolling sample of around 100,000 respondents in ca. 40,000 households, who are interviewed in five consecutive quarters. The rationale for using the UKLFS alongside the UKHLS is twofold. First, with the UKLFS we can extent our observation window almost up to date and include respondents who entered the UK labour market until 2017. Second, the UKLFS helps us to resolve certain methodological issues that we face when constructing our measure of social class as discussed below.

As said in the Introduction, we understand social class as deriving from employment relations. An individual's class position therefore depends on her employment status, i.e. whether she is employed, employing others or self-employed, and the type of contract governing her employment if she works as an employee. Different employment contracts exist because of different skill requirements and monitoring problems arising from the specific work tasks to be performed. It has been shown that in the case of employees, type of occupation serves as a reliable proxy for employment contracts and relations and can therefore be used to identify class positions. Given their strong association with socio-economic outcomes such as unemployment, income security, income stability, income prospects and wealth (Bukodi and Goldthorpe 2018), social classes can be hierarchically ordered.

For the UK, the National Statistics Socio-Economic Classification (NS-SEC) has been conceived to construct social class in exactly this way. We therefore use the NS-SEC to operationalise social class in the UKHLS and UKLFS. For Germany, we use its closest equivalent, the European Socioeconomic Classification (ESeC). The $\mathrm{ESeC}$ has the same theoretical underpinning as the NS-SEC and has been developed to facilitate comparative research across European countries (Rose and Harrison 2010). Table 1 presents the 7-class version of the two schemes.

Germany. We run robustness checks to account for selective migration from East to West Germany after 1989. Our results remain unchanged when excluding respondents born in East Germany (see Appendix C). 
Table 1. The seven-class versions of the European Socio-Economic Classification (ESeC) and National Statistics Socio-Economic Classification (NS-SEC)

\begin{tabular}{|c|c|c|}
\hline & ESeC & NS-SEC \\
\hline Class 1 & $\begin{array}{l}\text { Large employers, higher managers and } \\
\text { professionals }\end{array}$ & $\begin{array}{l}\text { Higher managerial, administrative and } \\
\text { professional occupations }\end{array}$ \\
\hline Class 2 & $\begin{array}{l}\text { Lower managers and professionals, } \\
\text { high-level supervisors }\end{array}$ & $\begin{array}{l}\text { Lower managerial, administrative and } \\
\text { professional occupations }\end{array}$ \\
\hline Class 3 & Intermediate occupations & Intermediate occupations \\
\hline Class 4 & Small employers and own account workers & Small employers and own account workers \\
\hline Class 5 & Lower supervisors and technicians & Lower supervisory and technical occupations \\
\hline Class 6 & Lower service, sales and technical occupations & Semi-routine occupations \\
\hline Class 7 & Routine occupations & Routine occupations \\
\hline
\end{tabular}

Note: The dashed lines indicate the hierarchical ordering of classes in the respective scheme.

Given our focus on the intergenerational class mobility of labour market entrants, respondents' origin class and class at labour market entry are our two key variables. In the SOEP and UKHLS, we use the dominance approach to construct origin class, which takes the higher class if father's and mother's class differ (Erikson 1984). Since the UKLFS only asks about the occupation of the main wage earner during childhood, we take this as approximation. In all three surveys, class of origin is established at respondents' age 14 .

Due to their longitudinal design, the SOEP and UKHLS have information, even if in part retrospectively, on respondents' full employment trajectories, including first job based on which class at labour market entry is constructed. The UKLFS, however, does not ask respondents about their first jobs, but provides information on the date when they completed their full-time education. Based on this, we select respondents who completed full-time education within one year of the interview and are in employment when surveyed. Given that in the UK, average job tenure amongst individuals below age 35 is around three years (OECD 2019), it is highly likely that these respondents are still working in their first jobs. To minimise the risk of capturing casual jobs during the school-to-work transition and re-entries into the labour market after periods of continuing education, we exclude in all surveys respondents who started their first jobs before age 14 or left full-time education after age 35 .

For Germany, the SOEP provides ISCO88 3-digit occupational codes as well as information on employment status, number of employees and supervisory functions for respondents and their parents. We are hence able to construct the 'full' version of $\mathrm{ESeC}$ based on the official crosswalk 
for both class origin and class at labour market entry according to the procedure in Rose and Harrison (2010).

For the UK, we use the official NS-SEC crosswalk that relies on the national occupational classification, i.e. SOC10 4-digits codes, alongside information on employment status, number of employees and supervisory functions. The UKLFS has all this information for the respondents. We can therefore construct the 'full' version of the NS-SEC to measure class at labour market entry. For class of origin, however, we need to revert to the 'simplified' version since only the occupation of the main wage earner in the parental household is known. Yet, as Table A4 (Appendix) shows, the allocation of NS-SEC according to the 'full' and 'simplified' method for class at labour market entry overlaps to a large extent. In the UKHLS, SOC10 codes are only provided in 3-digits for both respondents and their parents. We therefore create our own crosswalk between SOC10 3-digits codes and NS-SEC classes based on the relevant distributions in the UKLFS, which are then used in the UKHLS to measure class origin and class at labour market entry according to the simplified version. ${ }^{4}$

To map trends over time, we follow the literature and adopt a cohort approach. Since we aim to do so for labour market entrants, we use labour market entry cohorts contrary to most of past research that relied on quasi-birth cohorts. Moreover, we aim to define these cohorts as narrowly as possible in order to give a detailed picture of change in intergenerational class mobility. In the SOEP, labour market entry is defined as the year in which respondents start their first job after having completed full-time education. In the UKHLS and UKLFS, we take the year in which respondents first left full-time education as a proxy, since no information on the precise date when respondents entered the labour market is available. ${ }^{5}$ In our two primary datasets, the SOEP and UKHLS, we then create 16 four-year cohorts, comprising of respondents who entered the labour market between 1950 and 2013. Given the UKLFS's large sample size, we can work with four annual labour market entry cohorts (2014-2017) in our secondary dataset for the UK.

As explained, the operationalisation of class origin and class at labour market entry is somewhat different in the two UK surveys. Class mobility rates are hence likely to differ to some extent. In particular, rates of relative mobility might be over-estimated in the UKLFS due to attenuation bias as class origin is measured less precisely based on the main wage earner and using an occupationonly-approach. ${ }^{6}$ Despite these measurement problems, we regard using the UKLFS as important to provide an up-to-date account of UK trends in intergenerational class mobility. Although mobility levels might be slightly different from those in the UKHLS, a close inspection of the UKLFS suggests that the size of the measurement error described above does not differ between

\footnotetext{
${ }^{4}$ More precisely, we take the full sample of the pooled 2014-2017 UKLFS July-September Quarters and construct the 7-class version of the NS-SEC for respondents' current employment and their main wage earner as outlined above. Respondents' last employment is taken if information on current employment is missing. We then turn the SOC10 4digits into 3-digits and determine for each of the latter the most common NS-SEC class position, separately for men, women and the main wage earner. Our gender- and generation-specific crosswalks thus rely on the mode NS-SEC constructed from SOC10 4-digits by SOC10 3-digits in the UKLFS.

${ }^{5}$ For 688 observations $(1.8 \%)$ in the UKHLS, year of leaving full-time education is missing. For these cases, we approximate year of labour market entry using mean age of leaving full-time education of those respondents, who have similar educational qualifications and were born within the same five years.

${ }^{6}$ If class origin is measured with greater error, its 'predictiveness' regarding class destination decreases and the association between class origin and class destination weakens. Thus, rates of relative mobility will be upwardly biased showing greater social fluidity than is actually the case (Erikson and Goldthorpe 2010). This is exactly what we observe as presented in Figure A1 (Appendix).
} 
survey years, or labour market entry cohorts, within the UKLFS. Thus, the estimates of over-time change yielded by the two datasets can be regarded as comparable.

Finally, we perform multiple imputation by chained equations, separately for men and women, on all three datasets to adjust for systematic missingness in class origin. ${ }^{7}$ In line with previous research (Betthäuser 2017), we find that individuals with lower class destinations are more likely to have missing information on their origin class than individuals with higher class destinations. After imputation, our analytical samples contain 31,885 (SOEP), 37,847 (UKHLS) and 6,770 (UKLFS) observations. Tables A1, A2, and A3 (Appendix) show the distributions of class origin and class at labour market entry by cohort and gender for each survey. All results presented draw on the multiply imputed datasets.

\section{Empirical results}

\section{Absolute mobility rates}

We calculate rates of total, upward and downward mobility for each of our labour market entry cohorts in Germany and the UK, separately for men and women. Total rates are calculated as the percentage of individuals, who were in a different class at labour market entry than that of their parents, based on the 7-class version of ESeC and NS-SEC. For upward and downward mobility, we use a 5-class collapse of both schemes since Classes 3, 4 and 5 cannot be hierarchically ordered (see Table 1). Upward (downward) rates are calculated as the percentage of individuals, who started their careers in a higher (lower) class position than their origin class.

Figures 1 and 2 show the absolute mobility rates with 95 per cent confidence intervals. Like previous research based on quasi-birth cohorts, we generally observe no significant change in total mobility for labour market entrants in either country. We also find similar levels of total mobility (70-80 per cent) as reported by prior studies. Country differences, however, emerge with respect to changes in the relative importance of upward and downward mobility. In Germany, upward mobility steadily increased, while downward mobility steadily decreased. From the 1960s onwards, the proportion of those starting their careers in a higher class than their class of origin gradually exceeded the proportion of those starting their careers in a lower class. In the UK, we see an opposite pattern. Upward mobility was in constant decline, while downward mobility constantly rose. Starting one's career in a lower class than that of one's parents became increasingly common since the 1970s. Data from the UKLFS confirms that this trend persisted for the most recent cohorts.

\footnotetext{
7 Besides year and class at labour market entry, we use available information on individuals' highest educational attainment, age at labour market entry, class at age 36 or older, $(\mathrm{log})$ income as well as parental education and labour market participation to predict missing information on class of origin. Class origin is imputed for $18.59 \%, 10.31 \%$ and $5.30 \%$ of the analytical sample in the SOEP, UKHLS, and UKLFS, respectively.
} 
Figure 1. Absolute mobility rates (\%), with $95 \%$ confidence intervals, by labour market entry cohort, Germany

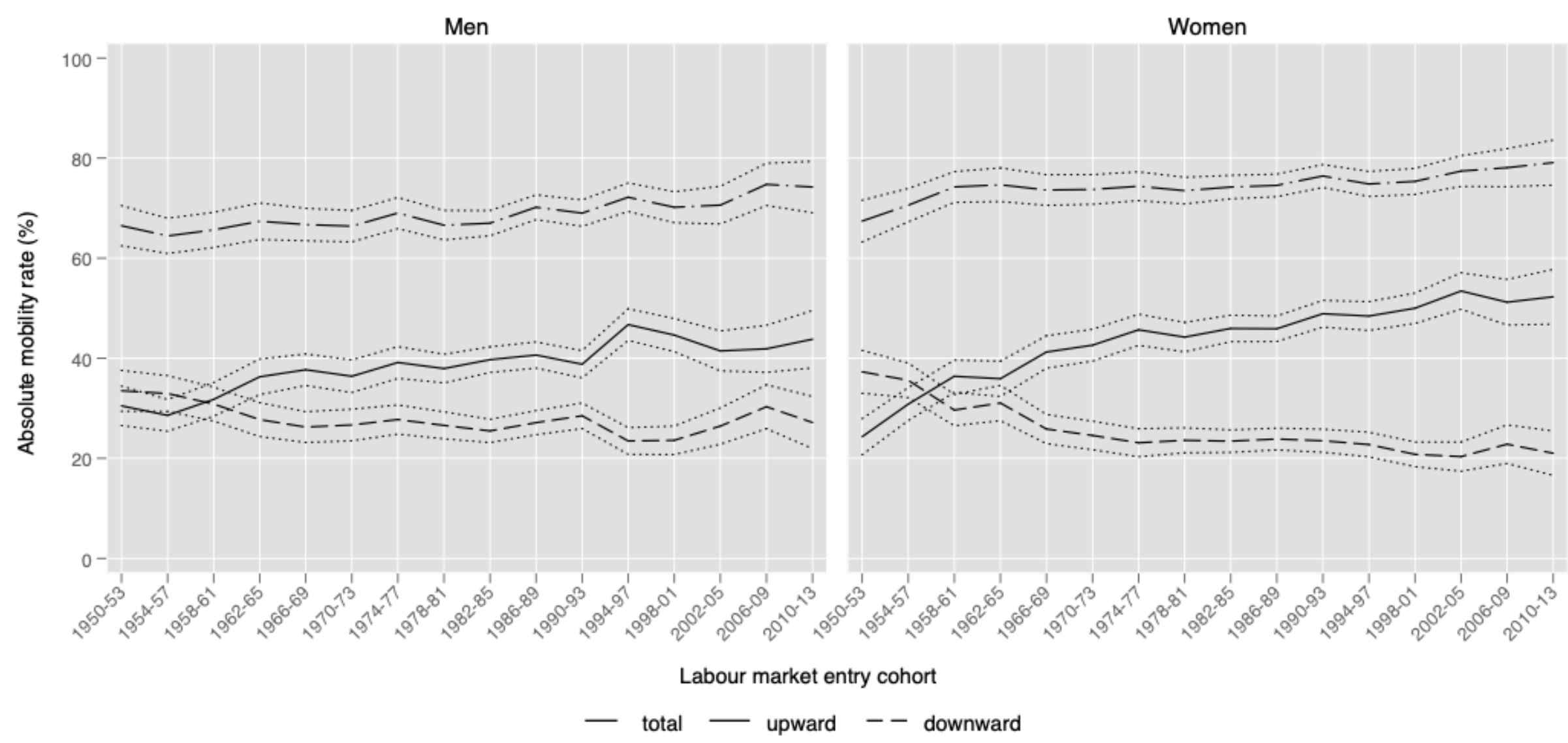

Note: $\mathrm{N}_{\mathrm{men}}=15,607 ; \mathrm{N}_{\text {women }}=16,278$.

Source: SOEP 1984-2016. 
Figure 2. Absolute mobility rates (\%), with $95 \%$ confidence intervals, by labour market entry cohort, UK

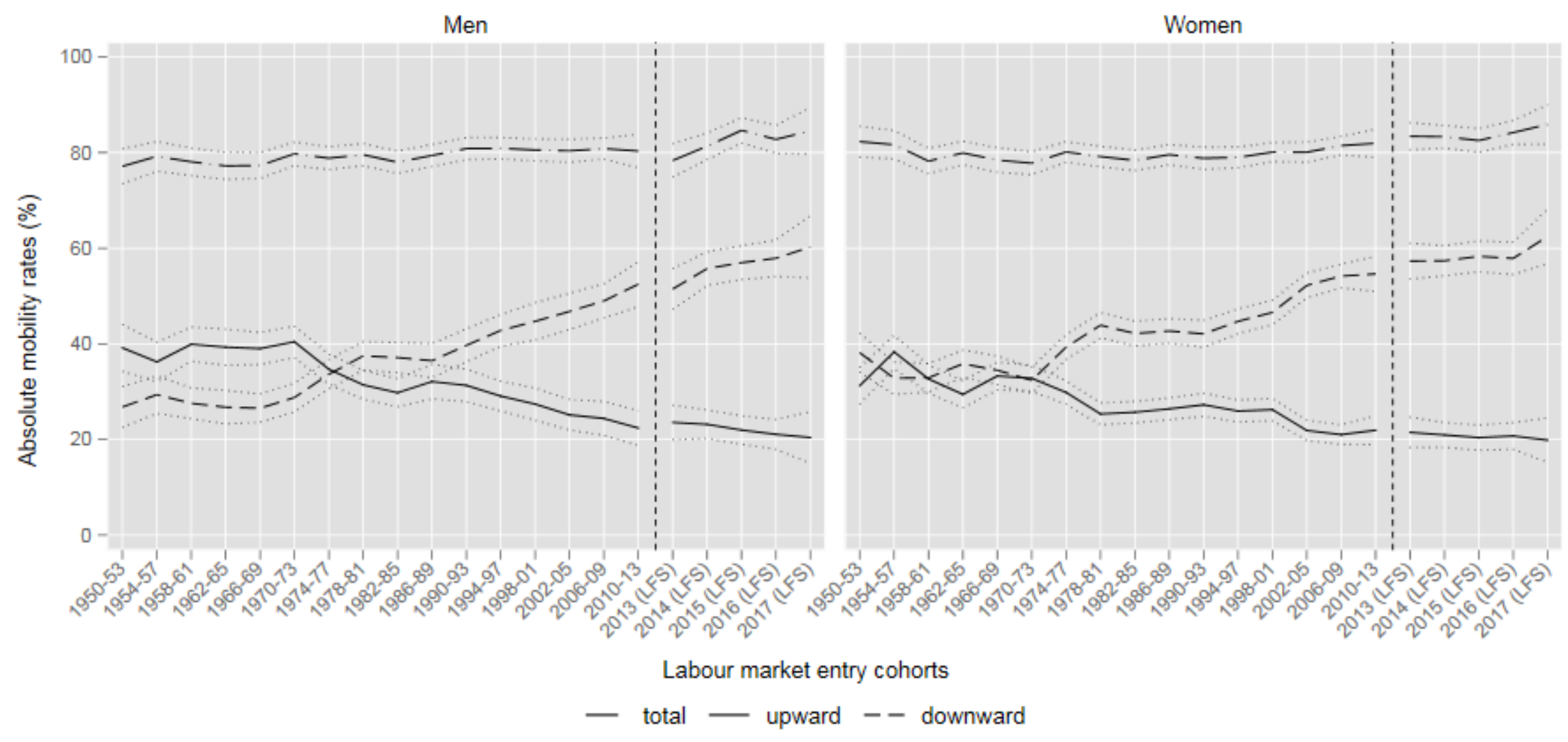

Note: $\mathrm{N}_{\text {men }}=17,019$ (UKHLS) / 3,025 (UKLFS); $\mathrm{N}_{\text {women }}=19,687$ (UKHLS) / 3,745 (UKLFS).

Source: UKHLS 2009-2013 EUL; UKLFS 2014-2017 Secure Access. 
The continuity in the trends of upward and downward mobility, which we observe for labour market entrants in both countries, stands somewhat in contrast to our expectations. For Germany, we expected to see similar trends to what was observed in past research, chiefly because class distributions, as we suggested, would look similar for individuals at different career stages in a context of low career mobility. Although our results of increasing upward mobility and decreasing downward mobility are in line with the findings of prior studies for individuals born during the first half of the twentieth century - most of whom entered the labour market between the 1930s and 1970s - we fail to discover a reversal of trends, i.e. increases in downward mobility and decreases in upward mobility for later cohorts. This suggests that career mobility might have become more important for members of later labour market entry cohorts relative to earlier cohorts. In fact, Becker and Blossfeld (2017) show that in Germany, increases in occupational prestige across individuals' working lives became increasingly steeper for those who entered the labour market from the 1970s onwards. Differences in class distributions, depending on when class destination is measured, may therefore be larger for later cohorts. Nevertheless, our expectation about country differences appears confirmed as we see divergent trends in the upward and downward rates of labour market entrants in Germany and the UK.

To see whether these divergent trends result from contrasting changes in the distribution of origin and destination classes, Figure 3 plots the proportion of respondents from salariat (Classes 1 and 2) origins and the proportion of respondents in salariat destinations for each labour market entry cohort in Germany and the UK. ${ }^{8}$ Although more pronounced in the UK, we observe for both countries a growing proportion of respondents with more advantaged class backgrounds, corroborating previous findings. In Germany, however, not only the proportion of respondents from salariat origins increased, but also the proportion of respondents in salariat destinations. The latter even started to overtake the former in the mid-1960s, improving chances for upward mobility and making downward mobility less likely for labour market entrants over time.

In the UK, only cohorts entering the labour market during the 1950s and 1960s - a period of exceptional economic growth and prosperity ${ }^{9}$ - saw an expansion in the proportion of salariat destinations that paralleled increases in the proportion of salariat origins. From the 1970s onwards, the proportion of respondents that began their careers in salariat destinations remained more or less stable. As the proportion of respondents coming from salariat origins yet continued to rise, so did the proportion of labour market entrants 'at risk of downward mobility' (Bukodi et al. 2019). The observed country differences in absolute mobility can therefore be attributed to divergent class structural changes for labour market entrants in Germany and the UK.

\footnotetext{
${ }^{8}$ We only show the development of the salariat as origin and destination classes across labour market entry cohorts. A more or less 'mirrored' picture of these developments can yet be observed when looking at the working class (Classes 6 and 7). The results are available upon request.

9 The reason why this period is sometimes referred to as Britain's 'golden age' of intergenerational mobility (Bukodi and Goldthorpe 2018).
} 
Figure 3. Proportion of respondents from salariat origins and proportion of respondents in salariat destinations at labour market entry by labour market entry cohort
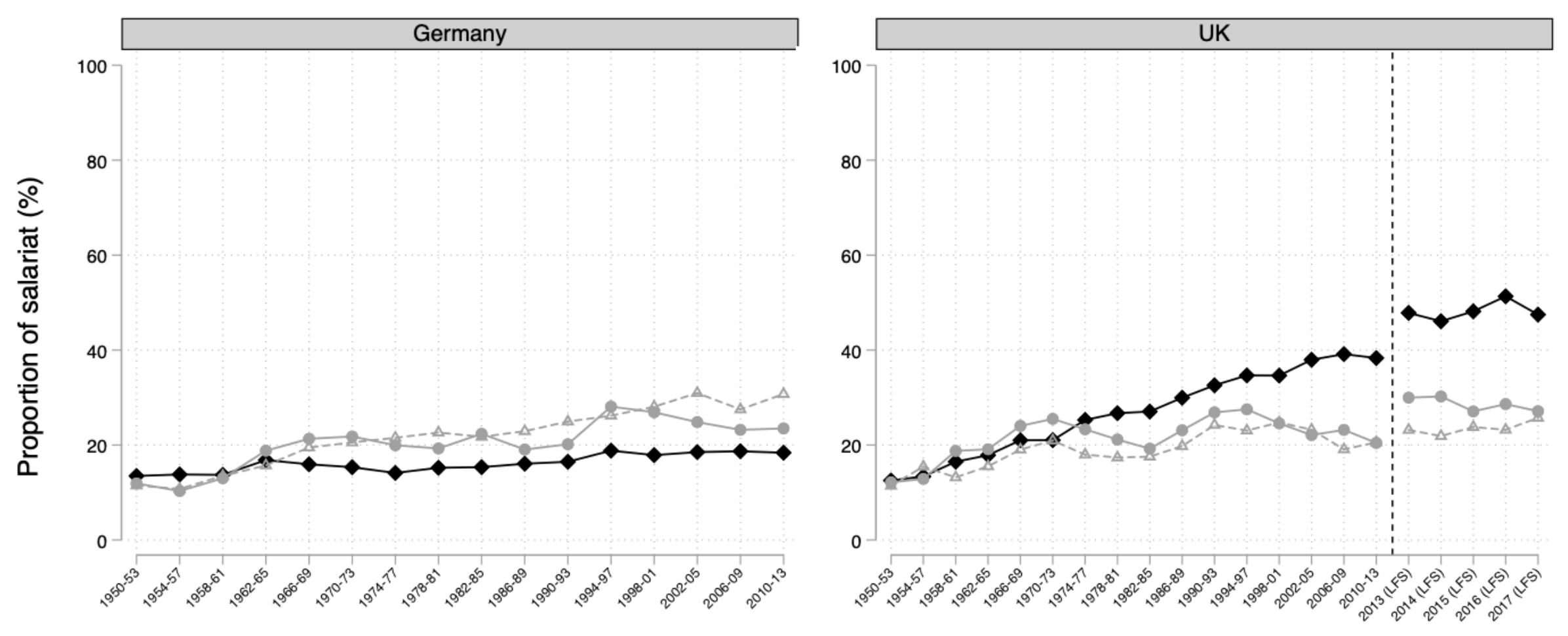

\section{Labour market entry cohort}

$\neg$ class of origin $\rightarrow-$ class at labour market entry (men) $\quad-\wedge$ class at labour market entry (women) 


\section{Relative mobility rates}

Since relative mobility considers the chances of individuals coming from different class origins being found in different class destinations net of class structural change, we use (log-)odds ratios to measure relative rates. For a mobility table that is based on a seven-class scheme like the ESeC or NS-SEC, $21^{2}=441$ odds ratios can be calculated, as there are $(7 \times 6) / 2=21$ pairs of origin and destination classes each. We have 16 mobility tables for Germany and 16 (UKHLS) +4 (UKLFS) tables for the UK for each gender, and so must deal with 31,752 odds ratios in total. Two different approaches are chosen to navigate such complexity that come with their own strengths and shortcomings.

Our first approach is adopted from Cox, Jackson, and $\mathrm{Lu}$ (2009), and is based on 'average global log-odds ratios' (AGLORs) (see also Dale 1984; Bukodi et al. 2019). The main advantage of AGLORs is that they provide a single summary measure of social fluidity for each mobility table and thereby enable straightforward cross-cohort comparisons. However, they require fully ordered class categories. We thus work with the five-class versions of ESeC and NS-SEC (see Table 1). The first step is then to partition each $5 \times 5$ mobility table into $162 \times 2$ sub-tables to calculate global logodds ratios. The first global log-odds ratio is calculated based on the table being divided between the first row and first column. The second is calculated based on the table being divided between the first row and first and second column. The third is calculated based on the table being divided between the first row and first, second, and third column and so on. We then average across all 16 global log-odds ratios. Formally,

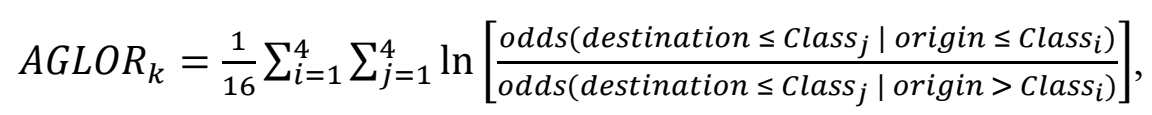

where $A G L O R_{k}$ is the average global log-odds ratio for labour market entry cohort $k$ based on a $5 \times 5$ mobility table. The higher the AGLOR, the stronger the net origin-destination association, i.e. the lower relative mobility.

Based on our primary datasets, Figure 4 plots the AGLOR for each labour market entry cohort by country. Especially for men, the origin-destination associations are generally stronger in Germany than in the UK. This is in line with previous research that identifies Germany as a low and the UK as a high fluidity country (Bukodi et al. 2019). More important for our purposes is yet the indication of a slight increase in social fluidity. In both countries, the origin-destination association seems to have weakened over the considered period, especially for women, as suggested by the downwardly sloping trend lines. However, we also see, especially for men, some levelling off of these increases for cohorts that entered the labour market since the mid-1970s. 
Figure 4. Average global log odds ratios by labour market entry cohort

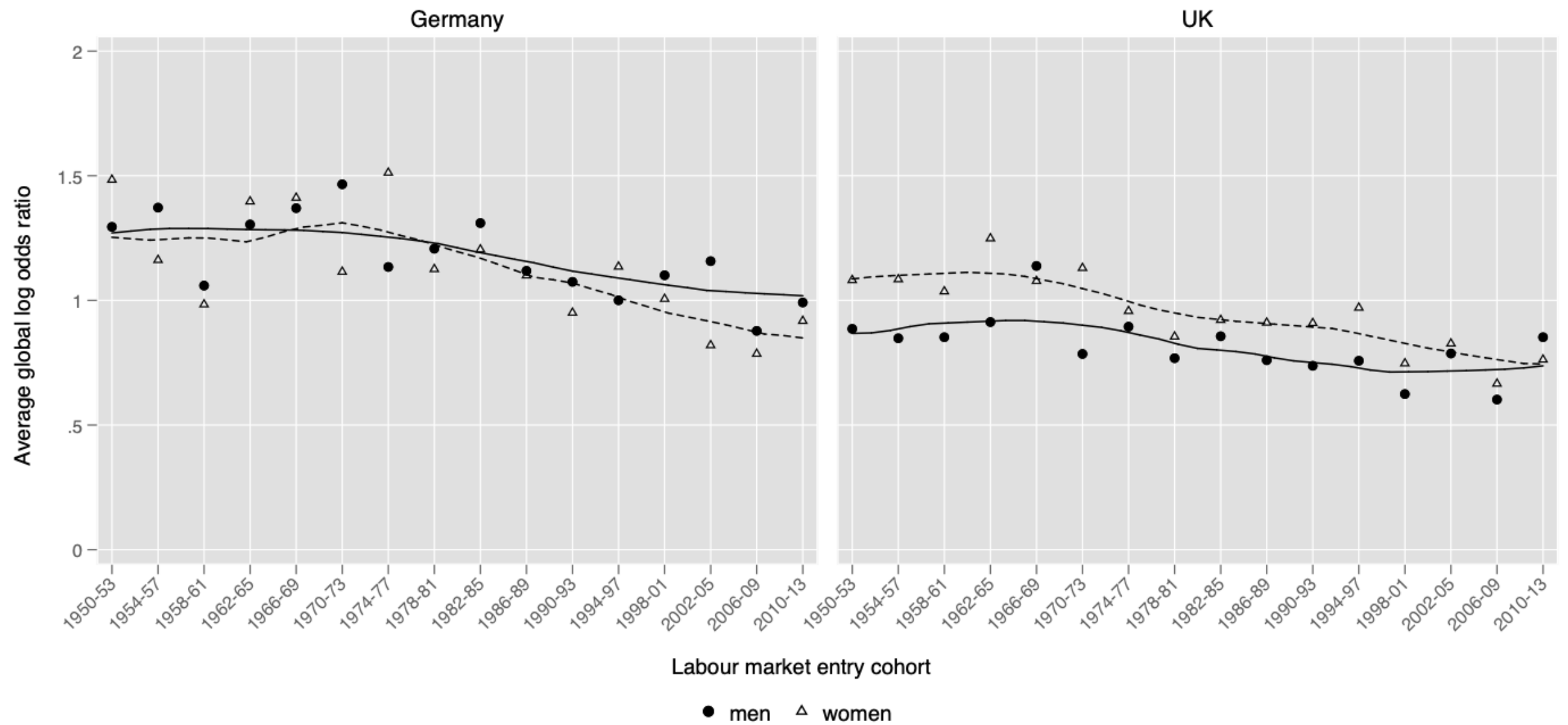

Note: Local polynomial smoothing applied for men (solid line) and women (dashed line). Source: SOEP 1984-2016, UKHLS 2009-2016 EUL 
Although easy to calculate and interpret, AGLORs are based on collapsed versions of ESeC and NS-SEC. They therefore mask horizontal mobility, which could bias the estimation of over-time trends if movements between Classes 3, 4, and 5 differed between cohorts. Our second approach hence follows more established sociological practice and fits two log-linear models on the 7-class version of ESeC and NS-SEC (for further elaboration see Breen 2004). The model of 'Constant Social Fluidity' (CnSF) assumes that the net origin-destination association does not differ across labour market entry cohorts and so remains constant over time:

$$
\log F_{i j k}=\mu+\lambda_{i}^{O}+\lambda_{i}^{D}+\lambda_{i}^{C}+\lambda_{i k}^{O C}+\lambda_{j k}^{D C}+\lambda_{i j}^{O D}
$$

where $F_{i j k}$ is the expected frequency in cell $i j k$ of a three-way table including origin $i(\mathrm{O})$, destination $j$ (D) and labour market entry cohort $k(\mathrm{C}), \mu$ is a scale factor, $\lambda_{i}^{O}, \lambda_{j}^{D}, \lambda_{k}^{C}$ are the main effects of the distributions of individuals over origins, destinations and cohorts, and $\lambda_{i k}^{O C}$ and $\lambda_{j k}^{D C}$ refer to the association between origin and cohort and destination and cohort, respectively. Finally, $\lambda_{i j}^{O D}$ represents the net association between origin and destination, for which the defining log-odds ratios are assumed to be the same across cohorts.

By contrast, the model of 'Uniform Differences' (UNIDIFF), also known as the log-multiplicative layer effects model (Erikson and Goldthorpe 1992; Xie 1992), allows the log-odds ratios to differ by a common cohort-specific factor $\beta_{k}$ - the UNIDIFF parameter:

$$
\log F_{i j k}=\mu+\lambda_{i}^{O}+\lambda_{i}^{D}+\lambda_{i}^{C}+\lambda_{i k}^{O C}+\lambda_{j k}^{D C}+\beta_{k} X_{i j}^{O D}
$$

where $X_{i j}^{O D}$ refers to the general pattern of the association between origins and destinations across cohorts. If $\beta_{k}<1$, the origin-destination association is weaker and relative rates are higher in cohort $k$ compared to a given reference cohort $\left(\beta_{\text {reference }}=1\right)$. If $\beta_{k}>1$, the origin-destination association is stronger and relative mobility rates are lower. The UNIDIFF thus accounts for cohort-specific differences in the origin-destination association that apply uniformly to all underlying log-odds ratios. Put differently, it allows cohorts to have consistently higher or lower levels of social fluidity. Being limited to capturing only uniform differences in social fluidity across cohorts is a disadvantage of the model compared to the AGLOR approach. However, as Tables A5 and A6 (Appendix) show, the model fits well on the observed data in both countries for almost all cohorts.

To give a thorough account of long-term trends, we apply what we call a 'moving windows' approach. Starting with the earliest labour market entry cohort (1950-53) as reference, we fit the $\mathrm{CnSF}$ and UNIDIFF models to compare its relative mobility rates to those of all subsequent cohorts. We then repeat this exercise using the next cohort (1953-57) as reference and so on, until the relative rates of the 2006-09 cohort are compared to those of the 2009-13 cohort. In total, we have 15 comparisons. Setting up the cross-cohort comparison in this way allows us to see to what extent the patterns of change in relative mobility depend on the cohorts considered and thus to more precisely identify the timing of change 
Figure 5. UNIDIFF parameters for labour market entry cohorts - "Moving windows approach", Germany

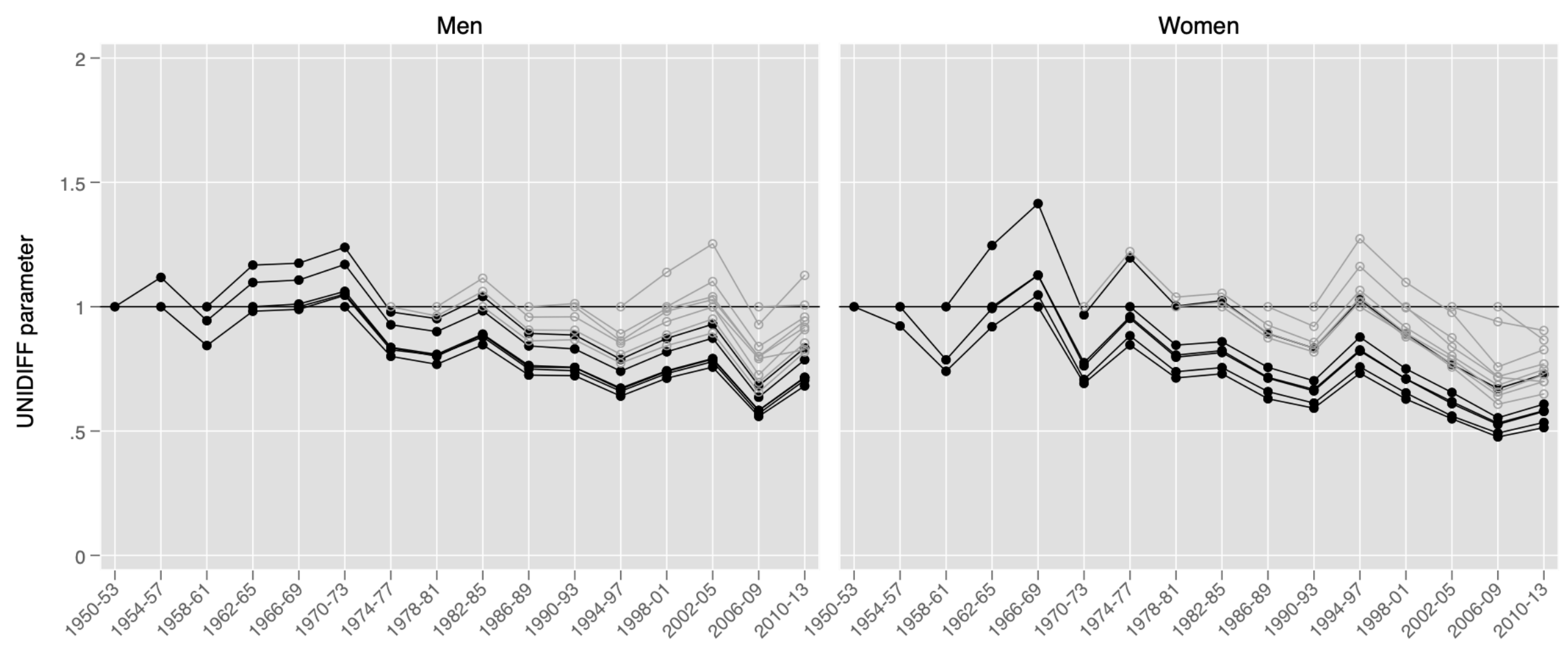

Labour market entry cohort

$\rightarrow$ UNDIFF improves on CnSF $-\odot$ UNDIFF does not improve on CnSF

Note: Fit statistics are presented in Table A5 in the Appendix.

Source: SOEP 1984-2016. 
Figure 6. UNIDIFF parameters for labour market entry cohorts - "Moving windows approach", UK

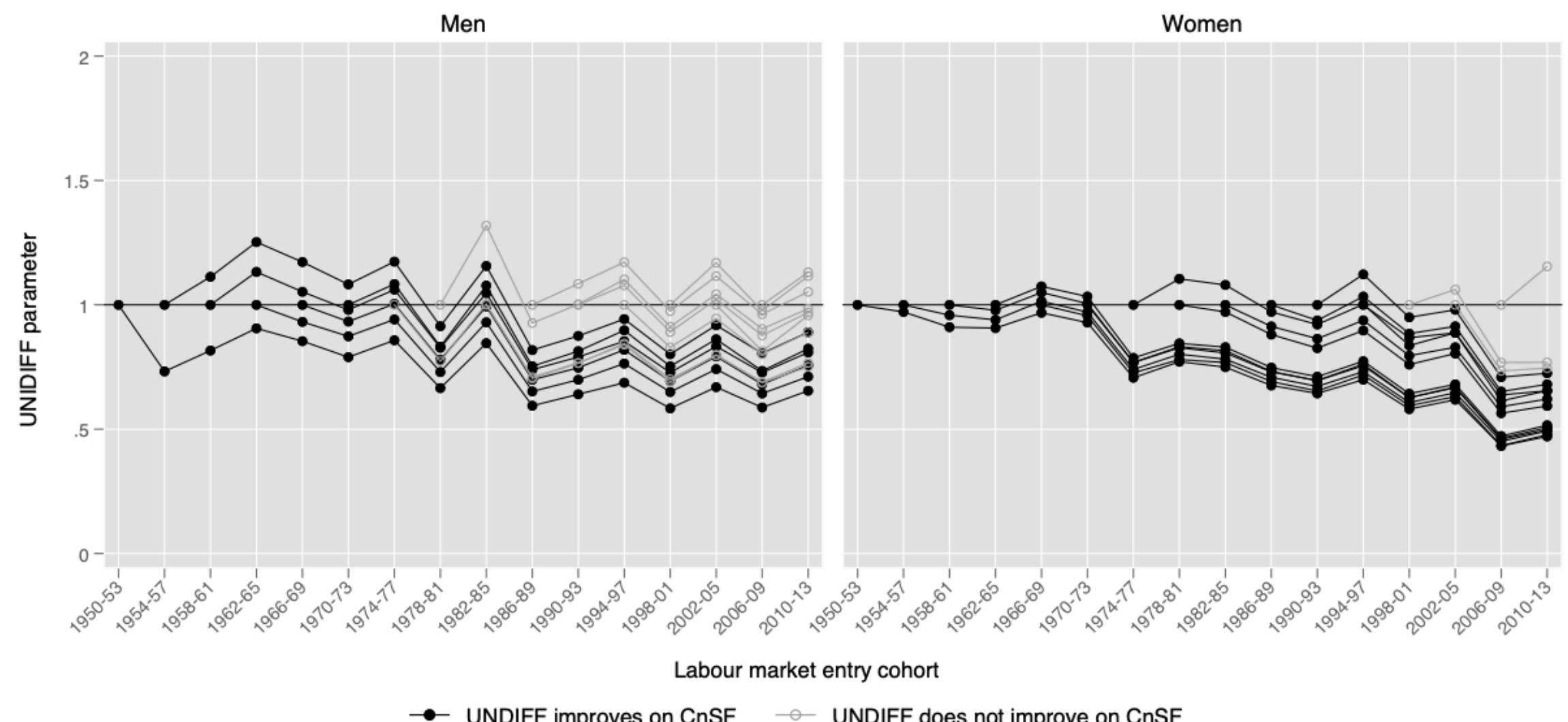

Note: Fit statistics are presented in Table A6 in the Appendix.

Source: UKHLS 2009-2016 EUL 
The results are shown in Figure 5 for Germany and in Figure 6 for the UK. When we compare cohorts that entered the labour market in the 1950s and 1960s with cohorts that entered the labour market in the 1970s and later, we again find evidence for increasing social fluidity, i.e. the UNIDIFF improves on the CnSF in both countries for both genders. Yet, when we only focus on those who started their careers after 1970, the picture is clearly different. The UNIDIFF no longer improves consistently on the CnSF, suggesting that increases in relative rates at labour market entry came to a halt. For German men and women as well as for British men, relative mobility essentially stopped increasing for those who entered the labour market since the first half of the 1970s. For British women, increases in relative mobility ceased to continue somewhat later, during the late-1990s.

Both of our methodological approaches then paint a picture of striking similarity for Germany and the UK regarding long-term trends in relative mobility: an overall increase that levels off for individuals who entered the labour market after the mid-1970s. How far are these results in line with our expectations set out earlier? For Germany, we expected trends in social fluidity to look similar regardless of when class destination is measured in individuals' working lives due to relatively low levels of career mobility. In contrast, for the UK, we expected trends in social fluidity to differ when class destination is measured at labour market entry as compared to more advanced career stages due to relatively high levels of career mobility. Both of these expectations are confirmed by our results. Like past research, we also find a 'halting increase' in social fluidity for Germany (Hertel 2017; Pollak and Müller 2020). Yet, the same pattern of trends is observed for the UK as well, which is at odds with previous studies that measure class destination at later career stages and report either overall stability or trendless fluctuation (Bukodi and Goldthorpe 2018).

By studying mobility rates over a 70 -year period, we contribute to the literature on long-term trends. However, we also aim to explore whether changes in social fluidity may be linked to shorterterm volatilities or cyclical changes in the economy and labour market. Past research already provided evidence for a negative impact of adverse economic conditions at labour market entry on future career progression that seems to vary for individuals from different social backgrounds (Blossfeld 1986, 1987; Bukodi and Goldthorpe 2011; Barone and Schizzerotto 2011). In a last step, we thus perform significance tests for differences in average global log-odds ratios (Figure7) ${ }^{10}$ and fit the CnSF and UNIDIFF models to mobility tables of pairs of adjacent cohorts (Figure 8). If relative mobility followed periods of 'boom' and 'bust', these should appear when looking at more granular cross-cohort comparisons.

\footnotetext{
10 More precisely, we divide the difference in the average central four of global log-odds ratios by the standard error of this difference as described by Cox et al. (2009). According to the authors, using the central set of global log-odds ratios is preferable as they give a more precise result.
} 
Figure 7. Significance test for differences in average global log odds ratios between adjacent labour market entry cohorts

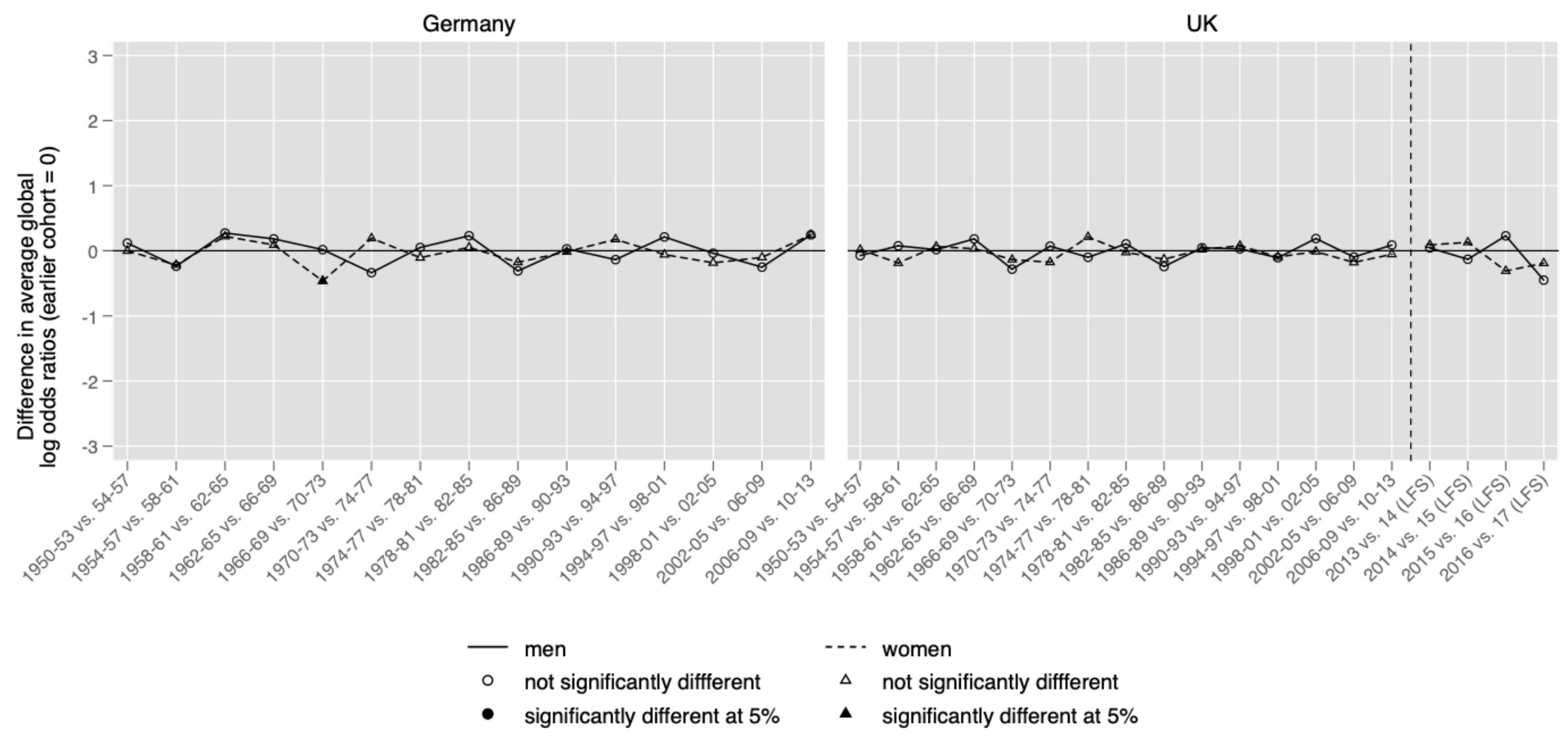

Note: SOEP 1984-2016, UKHLS 2009-2016 EUL; UKLFS 2014-2017 Secure Access. 
Figure 8. Results of fitting the CnSF and the UNIDIFF models

to adjacent labour market entry cohorts

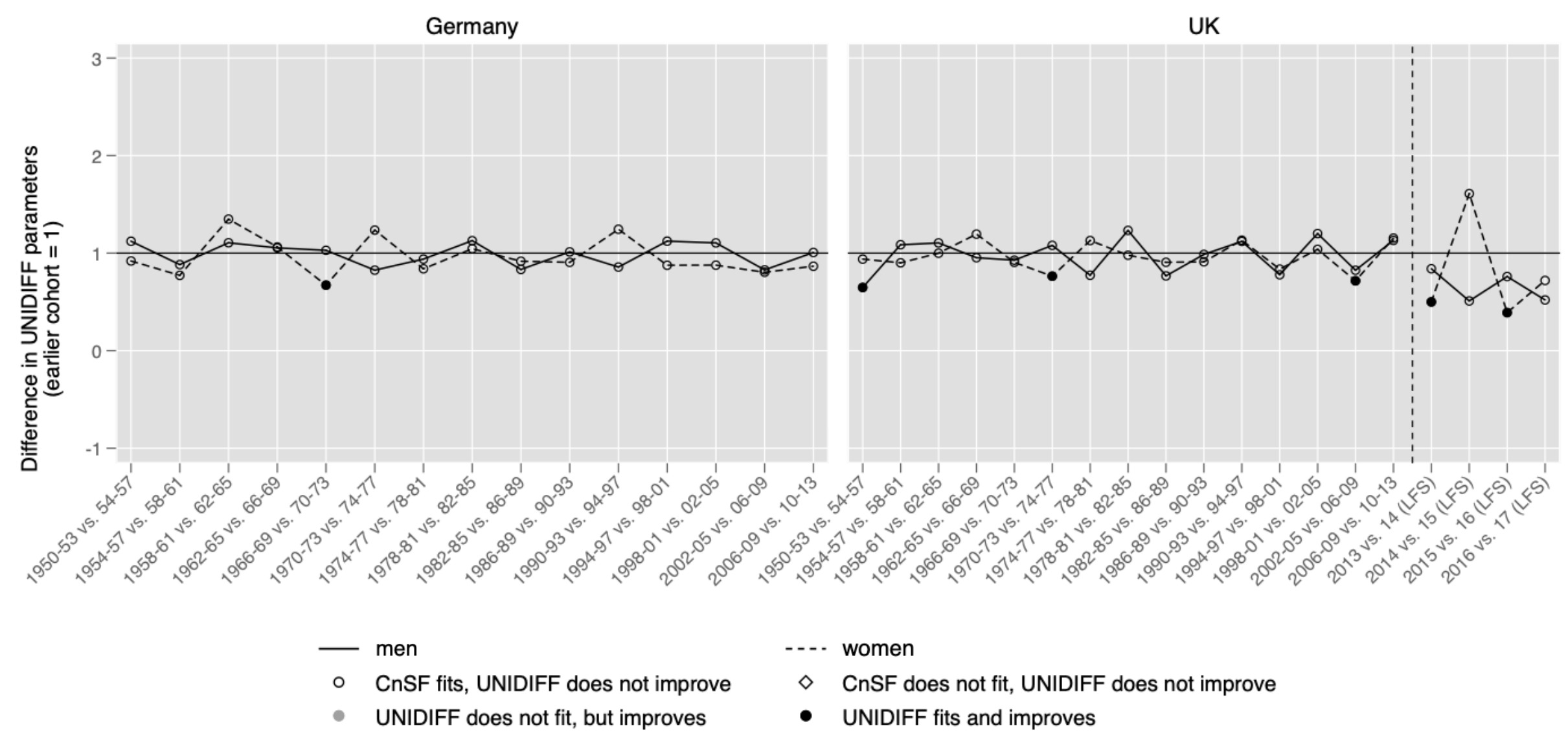

Note: Fit statistics are presented in Tables A7 and A8 in the Appendix.

Source: SOEP 1984-2016, UKHLS 2009-2016 EUL; UKLFS 2014-2017 Secure Access 
Despite visible fluctuations, we do not find consistent differences in relative mobility rates between pairs of adjacent cohorts. ${ }^{11}$ Insofar as there are significant differences, these show up in a rather unsystematic way and can neither be related to periods of growth nor crisis. For example, the UK was hit by a severe recession at the beginning of the 1980s and privatisation, extensive deregulation and labour market re-structuring further contributed to soaring unemployment rates and economic inequality throughout the decade. Based on past research (Bukodi and Goldthorpe 2011), we expected individuals who entered the labour market during this time to experience decreases in social fluidity as class origin appears to matter more when economic conditions are critical. However, we do not observe a strengthening in the origin-destination association between the 1978-81 and 1982-85 cohorts. Likewise, the 2008 financial crisis had a large impact on the economies of Germany and the UK, leading to negative growth rates in both countries. We nevertheless see no decline in the level of social fluidity for the 2006-09 cohort compared to the 2002-05 cohort in either country. Short-term changes in economic conditions or labour market volatilities therefore do not seem to be associated with significant changes in relative mobility for labour market entrants. Notwithstanding, entering the labour market under unfavourable conditions may still have detrimental effects on individuals' career progression as shown by past research.

\section{Auxiliary analyses on relative rates}

We focus on individuals' first job in order to map long-term trends in intergenerational mobility that are 'adjusted' for intragenerational mobility, and to explore the degree to which conditions at labour market entry may shape chances for relative mobility. To take account of cross-national differences in the extent to which first job is predictive of individuals' class destinations over the course of their careers, we conduct our analyses for Germany and the UK. The two countries are known for their contrasting patterns of career mobility due to distinct institutional arrangements (Blossfeld et al. 2008). However, labour market entries and the nature of first jobs do not only differ between countries but are also changing over time. To assess how far these changes affect our trend estimates, we conduct an additional set of auxiliary analyses. ${ }^{12}$

As shown in Figures B1 and B2 (Appendix), the proportion of young workers found in some kind of 'non-standard' jobs, such as part-time or temporary employment, considerably increased over the past decades in our two countries (see also Bachmann et al. 2018; Allmendinger et al. 2013; Passaretta and Wolbers 2019). This growing flexibility may not only change patterns of labour market entry but can also affect changes in relative mobility rates, if the strength in the origindestination association differed for individuals in standard and non-standard employment.

Indeed, we observe some significant differences in the origin-destination association between the two groups that is particularly pronounced for younger respondents in the UK (Tables B1 and B2). Yet, given that labour market entrants have become older over time as a result of longer educational trajectories (Bachmann et al. 2018), this effect can be expected to be rather neglibible. Nevertheless, we further check for systematic differences in relative mobility rates between older and younger

\footnotetext{
11 We obtain similar results if we compare cohorts over a period of 16 years by replacing the 4-year labour market entry cohorts by 8 -year cohorts. The results are presented in Figures A2 and A3 (Appendix).

12 Due to space limitation, we can only give a brief summary, but detailed elaboration on what we do and all results from this exercise are presented in full in Appendix B.
} 
labour market entrants. As no differences appear in both countries (Table B3), we are confident that the growing proportion of non-standard employment among labour market entrants is unlikely to affect our findings.

\section{Conclusion}

Focussing on cohorts of labour market entrants, our objective is to offer a refinement of the study of over-time trends in intergenerational class mobility. We believe that this approach pinpoints changes in absolute and relative mobility more precisely than approaches relying on quasi-birth cohorts for two reasons. First, members of different cohorts are compared with each other when they are at similar stages in their careers. Cohort differences can therefore be unambiguously attributed to differences in intergenerational class mobility rather than also involving differences in intragenerational class mobility. Second, members of the same labour market entry cohort start their careers under similar institutional and economic conditions. The approach thus exactly accounts for the opportunity structures members of different cohorts are faced with, allowing to further scrutinise how far conditions at labour market entry shape chances for intergenerational class mobility.

To gauge the degree to which differences in observed trends in intergenerational class mobility between individuals at different career stages depend on levels of career mobility, we study men and women who entered the labour market in Germany and the UK between the 1950s and 2010s. As expected, our results for Germany show great similarity with those of previous studies, while our findings for the UK are somewhat different. It therefore seems that in contexts with low levels of career or work-life mobility such as Germany, trends in intergenerational class mobility based on labour market entrants provide a reliable prediction of trends in intergenerational class mobility at all career stages. In other words, scholars do not necessarily need to 'wait' until survey respondents spent certain amounts of time in the labour market as chances for intergenerational class mobility seem to be determined from the very start. However, an important assumption is that levels of career mobility remain constant over time. By contrast, in contexts with high levels of career mobility such as the UK, the timing when to measure class destination is quite consequential. Compared to previous studies that measure individuals' class destination at later career stages, we 'overestimate', at least to some extent, decreases in upward mobility, increases in downward mobility as well as increases in relative mobility. Or, put differently, we 'underestimate' persistence in intergenerational inequality, when focussing on those who just embarked on their careers.

In addition, our results highlight how patterns of change in social fluidity are crucially affected by the design of the cross-cohort comparison. When looking at the entire period covered by our study, we do observe a weakening of the origin-destination association for both Germany and the UK. Our 'moving windows' approach yet reveals that earlier increases in social fluidity levelled off for cohorts who entered the labour market since the mid-1970s. Furthermore, more fine-grained comparisons between adjacent labour market entry cohorts do not provide evidence that social fluidity follows cyclical developments of the economy or shorter-term volatilities in the labour market. In both countries, increases in social fluidity appear to progress rather slowly and came to a halt towards the end of the twentieth century. 
The finding of very similar trends in social fluidity for labour market entrants in Germany and the UK warrants further reflection and raises the question to what extent initial increases that are followed by stability can be explained by historic idiosyncrasies of the two countries, that simply coincided in their timing, or are in fact related to a common factor. Our results cast some doubt on the universal applicability of an education-based explanation that was put forward to account for the halting increases in social fluidity observed for quasi-birth cohorts (Breen and Müller 2020). In the UK, contrary to Germany, the OE and ED associations did not change much in the second half of the twentieth century. Moreover, the OED interaction that allows to assign education a central role in increasing social fluidity does not appear to be significant either (Bukodi and Goldthorpe 2016).

An alternative explanation accounting for the lack of sustained increases in both countries, but in the UK in particular, may be found in the possibility of a structural 'limit' in social fluidity as suggested by Bukodi and Goldthorpe (2018). In societies with a capitalist market economy, nuclear family system and liberal-democratic policy, such limit could exist as more advantaged families always seek to use their superior resources - economic, cultural or social - to maintain their children's greater chances of success relative to those of children from less advantaged families. Beyond a certain point, parents may therefore block policy interventions aimed at creating greater educational equality or find some other ways for their children to avoid intergenerational downward mobility. This may become especially pressing at times when there is less 'room at the top', making it more difficult for children from advantaged backgrounds to maintain their parents' class positions. As we are unable to provide further evidence on the existence of such a limit in this paper, we leave its exploration to future research. However, as the absence of sustained increases in social fluidity are observed in two very different institutional contexts, explaining stability in relative rates might be one of the major puzzles to be solved by mobility scholars of the twenty-first century. 


\section{References}

Allmendinger,J, L.Hipp, and S.Stuth. 2013. 'Atypical Employment in Europe 1996-2011'. WZB Discussion Paper.

Bachmann,R, R.Felder, and M.Tamm. 2018. 'Labour Market Participation and Atypical Employment over the Life Cycle: A Cohort Analysis for Germany'. IZA Discussion Paper.

Barbieri,P, G.Cutuli, and G.Passaretta. 2016. 'Institutions and the school-to-work transition: disentangling the role of the macro-institutional context'. Socio-Economic Review 16(1):161-183.

Barone,C, and A.Schizzerotto. 2011. 'Introduction'. European Societies 13(3):331-345.

Becker,R. and H.-P.Blossfeld. 2017. 'Entry of men into the labour market in West Germany and their career mobility (1945-2008)'. Journal of Labour Market Research 50:113-130.

Bell,D. 1972. 'On Meritocracy and Equality'. Public Interest 29:29-68.

Betthäuser,B. 2017. 'Fostering Equality of Opportunity? Compulsory Schooling Reform and Social Mobility in Germany'. European Sociological Review 33(5):633-44.

Blossfeld,H-P. 1986. 'Career Opportunities in the Federal Republic of Germany, a Dynamic Approach to Study Life Course, Cohort and Period Effects'. European Sociological Revien 2(3):208-25.

. 1987. 'Entry into the Labor Market and Occupational Career in the Federal Republic: A Comparison with American Studies'. International Journal of Sociology 17(1-2):86-115.

Blossfeld,H-P, S.Buchholz, E.Bukodi, E.Ebralidze, K.Kurz, I.Relikowski, and P.Schmelzer. 2005. 'Flexibility processes and social inequalities at labor market entry and in the early career'. flexCAREER Working Paper Series.

Blossfeld,H-P, S.Buchholz, E.Bukodi, K.Kurz(eds). 2008. Young Workers, Globalization and the Labour Market: Comparing Early Working Life in Eleven Countries. Cheltenham:Edward Elgar.

Breen,R(ed). 2004. Social Mobility in Europe. Oxford:Oxford University Press.

Breen,R, and J.Jonsson. 2007. 'Explaining Change in Social Fluidity: Educational Equalization and Educational Expansion in Twentieth-Century Sweden'. American Joumal of Sociology 112(6):1775-1810.

Breen,R, and R.Luijkx. 2004. 'Social Mobility in Europe between 1970 and 2000'. In Social Mobility in Europe, R. Breen(ed). Oxford:Oxford University Press.

Breen,R, R.Luijkx, W.Müller, and R.Pollak. 2009. 'Nonpersistent inequality in educational attainment: Evidence from eight European countries'. American Journal of Sociology, 114(5):14751521.

Breen,R. and W.Müller(eds). 2020. Education and intergenerational social mobility in Europe and the United States. Stanford:Stanford University Press.

Bukodi, E. 2017. 'Cumulative Inequalities over the Life-Course: Life-Long Learning and Social Mobility in Britain'. Journal of Social Policy 46:367-404. 
Bukodi,E. and J.Goldthorpe. 2009. 'Class Origins, Education and Occupational Attainment: CrossCohort Changes among Men in Britain'. CLS Working Paper 2009/3. London:Centre for Longitudinal Studies, Institute of Education.

-.. 2016. 'Educational Attainment - Relative or Absolute - as a Mediator of Intergenerational Class Mobility in Britain'. Research in Social Stratification and Mobility 43:5-15.

. 2011. 'Class Origins, Education and Occupational Attainment in Britain'. European Societies 13(3):347-75.

- 2018. Social Mobility and Education in Britain: Research, Politics and Policy. Cambridge:Cambridge University Press.

Bukodi,E, J.Goldthorpe, L. Waller, and J.Kuha. 2015. 'The Mobility Problem in Britain: New Findings from the Analysis of Birth Cohort Data'. The British Journal of Sociology 66(1):93-117.

Bukodi,E, M.Paskov, and B.Nolan. 2019. 'Intergenerational Class Mobility in Europe: A New Account'. Social Forces.

Buscha,F, and P.Sturgis. 2018. 'Declining social mobility? Evidence from five linked census in England and Wales 1971-2011'. The British Journal of Sociology 69(1):154-82.

Cox,D, M.Jackson, and S.Lu. 2009. 'On Square Ordinal Contingency Tables: A Comparison of Social Class and Income Mobility for the Same Individuals'. Journal of the Royal Statistical Society 172(2):483-93.

Dale,J. 1984. 'Local versus Global Association for Bivariate Ordered Responses'. Biometrika 71(3):507-14.

Erikson,R. 1984. 'Social Class of Men, Women and Families'. Sociology 18(4):500-514.

Erikson,R, and J.Goldthorpe. 1992. The Constant Flux: A Study of Class Mobility in Industrial Societies. Oxford:Clarendon Press.

2010. 'Has Social Mobility in Britain Decreased? Reconciling Divergent Findings on Income and Class Mobility'. The British Journal of Sociology 61(2):211-30.

Featherman,D, and R.Hauser. 1978. Opportunity and Change. New York:Academic Press.

Ganzeboom,H, R.Luijkx, and D.Treiman. 1989. 'Intergenerational Class Mobility in Comparative Perspective'. Research in Social Stratification and Mobility 8:3-84.

Goldthorpe,J, and M.Jackson. 2007. 'Intergenerational Class Mobility in Contemporary Britain: Political Concerns and Empirical Findings'. The British Journal of Sociology 58(4):525-46.

Goldthorpe,J, C. Llewellyn, and C.Payne. 1987. Social mobility and class structure in modern Britain. Oxford:Oxford University Press.

Goldthorpe,J, and C.Mills. 2004. 'Trends in Intergenerational Class Mobility in Britain in the Late Twentieth Century'. In Social Mobility in Europe, R. Breen(ed). Oxford:Oxford University Press.

Groh-Samberg,O. 2009. Armut, soziale Ausgrenzung und Klassenstruktur: zur Integration multidimensionaler und längsschnittlicher Perspektiven. Wiesbaden:VS Verlag für Sozialwissenschaften.

Gugushvili,A., E.Bukodi, and J.Goldthorpe. 2017. 'The Direct Effect of Social Origins on Social Mobility Chances: 'Glass Floors' and 'Glass Ceilings' in Britain'. European Sociological Review 33(2): 305-316. 
Hertel,F. 2017. Social Mobility in the 20th Century: Class Mobility and Occupational Change in the United States and Germany. Wiesbaden:Springer VS.

Hout,M. 1988. 'More Universalism, Less Structural Mobility: The American Occupational Structure in the 1980s'. American Journal of Sociology 93(6):1358-1400.

Jackson, M, J.Goldthorpe, and C.Mills. 2005. 'Education, Employers and Class Mobility'. Research in Social Stratification and Mobility 23:3-34.

Jonsson,J, and C.Mills. 1993. 'Social Mobility in the 1970s and 1980s: A Study of Men and Women in England and Sweden'. European Sociological Review 9(3):229-48.

Lareau,A, and D.Conley. 2008. Social Class: How Does it Work? New York:Russell Sage Foundation.

Leuze,K. 2007. 'What Makes for a Good Start? Consequences of Occupation-Specific Higher Education for Career Mobility: Germany and Great Britain Compared.' International Journal of Sociology 37(2):29-53.

Mayer,K, and S.Aisenbrey. 2007. 'Variations on a Theme: Trends in Soical Mobility in (West) Germany for Cohorts Born between 1919 and 1971'. In From Origin to Destination, S.Scherer, R.Pollack, G.Otte, and M.Gangl(eds). Frankfurt am Main:Campus.

Müller,W, and R.Pollak. 2004. 'Social Mobility in West Germany: The Long Arms of History Discovered?' In Social Mobility in Europe, R. Breen(ed). Oxford:Oxford University Press.

. 2015. 'Bildung und soziale Mobilität in Deutschland'. AStA Wirtschafts- und Sozialstatistisches Archiv 9(1):5-26.

OECD 2019. 'Labour Force Statistics: Population and labour force', OECD Employment and Labour Market Statistics (database), https://doi.org/10.1787/data-00288-en (accessed on 2 April 2019).

Office for National Statistics, Social Survey Division, Northern Ireland Statistics and Research Agency, Central Survey Unit. 2018. Quarterly Labour Force Survey, 1992-2017: Secure Access. $12^{\text {th }}$ Edition. UK Data Service. http://doi.org/10.5255/UKDA-SN-6727-13.

Passaretta,G, and M.Wolbers. 2019. 'Temporary Employment at Labour Market Entry in Europe: Labour Market Dualism, Transitions to Secure Employment and Upward Mobility'. Economic and Industrial Democracy 40(2):382-408.

Paterson,L, and C.Iannelli. 2008. 'Patterns of Absolute and Relative Social Mobility: A Comparative Study of England, Wales and Scotland'. Sociological Research Online 12(6):1-21.

Pollak,R, and W.Müller. 2020. 'Education as an Equalizing Force: How Declining Educational Inequality and Educational Expansion Have Contributed to More Social Fluidity in Germany'. In Education and Intergenerational Social Mobility in Europe and the United States, R.Breen and W.Müller(eds). Stanford:Stanford University Press.

Rose,D, and E.Harrison(eds). 2010. Social Class in Europe: An Introduction to the European SocioEconomic Classification. London/New York:Routledge.

Ryder,N. 1965. 'The Cohort as a Concept in the Study of Social Change Author'. American Sociological Review 30(6):843-61. 
Scherer,S. 2005. 'Patterns of Labour Market Entry - Long Wait or Career Instability? An Empirical Comparison of Italy, Great Britain and West Germany.' European Sociological Review 21(5):427440 .

SOEP. 2018. Socio-Economic Panel (SOEP), data from 1984-2016. http://doi.org/10.5684/soep.v33.

Treiman,D. 1970. 'Industrialization and Social Stratification'. Sociological Inquiry 40(2):207-234.

University of Essex, Institute for Social and Economic Research. 2017. Understanding Society: W aves 1-7, 2009-2016 and Harmonised BHPS Waves 1-18, 1991-2009. $9^{\text {th }}$ Edition. UK Data Service. http://doi.org/10.5255/UKDA-SN-6614-10.

Wolbers,M. 2007. 'Patterns of Labour Market Entry: A Comparative Perspective on School-toWork Transitions in 11 European Countries'. Acta Sociologica 50(3): 189-210.

Xie,Y. 1992. 'The Log-Multiplicative Layer Effect Model for Comparing Mobility Tables'. American Sociological Review 57(3):380-380. 